\title{
Participation of dopaminergic system in the dynamics of behavioral reactions of aging rats of both sexes under daily testing in the open field
}

\author{
Elena Birukova ${ }^{1 *}$, Denis Khusainov ${ }^{1}$, Andrew Chajka $^{1}$, Natalya Tribrat $^{1}$, Zera Dzhemalyadinova $^{1}$, Natalia $_{\text {Dmitrenko }}{ }^{1}$ \\ and Svitlana Chornobay ${ }^{1}$ \\ ${ }^{1}$ Taurida Academy, V.I. Vernadsky Crimean Federal University, Simferopol, Russia
}

\begin{abstract}
Under daily testing of aging rats of both sexes in the open field a slow lowering of motion activity is observed: by the 6th day of the experiment the passed distance of male rats reduces by $41 \%(\mathrm{p} \leq 0.01)$, and of female rats - by $46 \%(\mathrm{p} \leq 0.05)$ in comparison to the background values. The blockade of monoamine oxidase-B (MAO-B) by selegiline (intraperitoneal introduction of $5 \mathrm{mg} / \mathrm{kg}$ one hour before testing) does not significantly change the orientation and intensity of this process, but probably contribute to the formation of a more comfortable psycho-emotional state of the animals. Consequently, the central dopamine cannot prevent from the motion activity lowering process of aging rats under daily testing, at least, in the frames of the experiment method used in this research. We obtained the evidence in favor of the fact that the suppression of the motion activity under daily testing is rather connected with the animals' loss of motivation for research than with the growing anxiety.
\end{abstract}

\section{Introduction}

It is well-known that in case of a repeated phenomenon of any modality and nature the interest to it is gradually lowering up to a complete suppression of its significance. Under the experimental laboratory conditions this suppression is manifested, for example, through lowering of such indicators as the passed distance, the exploratory activity, the time and amount of going out to the centre [1, 2]. On the whole, an animal stops exploring the testing space and demonstrates a passive behaviour. The factors, which influence the dynamics of this process, are still being actively discussed in the scientific community [2]. Thus, on the issue of the central dopamine participation there are data on the suppression of motion activity [3], as well as its stimulation [4], or even on the absence of the obvious effect [5]. The presence of antidepressant and anxiolytic effects is observed [3, 6], as well as the grooming stimulation $[7,8]$, or, on the contrary, the absence of meaningful psycho-emotional behavioral reactions [9].

\subsection{Purpose of the study}

Thus, we have put forward the hypothesis that the increase of the central dopamine concentration by blocking MAO$B$ may quantitatively and qualitatively influence the dynamics of motion activity and the anxiety level of both sexes rats in the open field, which is caused by the repeated 6-day testing.

\section{Experimental}

For the experimental work 30 male rats of Wistar type $(320-350$ gr., $15.5-16$ months) with an average level of motion activity and anxiety were selected. Further, the selected animals were divided into 3 groups: "Control" $(\mathrm{n}=10)$, "Placebo" $(\mathrm{n}=10)$ and "Selegiline" $(\mathrm{n}=10)$; and were left for ten days under standard conditions of the vivarium for a social adaptation. On the expiry of this period the animals from all the groups were tested daily in the circular open field with the diameter $1 \mathrm{~m}$ during 6 days in succession. From the vivarium the animals were taken to the ethology laboratory at 11.00 , for one hour they were left alone to adapt to the laboratory conditions, then at 12.00 they were injected, and at 13.00 the test started. The rats from Group "Control" did not undergo any additional influences, the rats from Group "Placebo" were daily injected intraperitoneally by $0.2 \mathrm{ml}$ of physiological solution 60 minutes before the test, the animals from Group "Selegiline" were injected the corresponding substance in the dose of $5 \mathrm{mg} / \mathrm{kg}$ in the volume of $0.2 \mathrm{ml}$. Testing of each individual lasted $5 \mathrm{~min}$, and before the experiment a so called zero rat was driven around in the behavioral test. The field was thoroughly wiped with a low-alcohol solution after each animal.

In the case with the female rats $(270-300$ gr., 15.5 16 months) all the groups and operations with them were identical to the ones with the male rats.

The animal grooming in both gender groups was also analyzed. We divided this indicator into three, more or

* Corresponding author: biotema@ rambler.ru 
less, definite forms: an interrupted grooming of separate body parts (discomfort marker), incomplete grooming and complete grooming (comfort marker). These forms are relative enough as till now there is no unanimity in the scientific community on the issue of classification and importance of grooming.

In a separate experimental series, the anxiety index (AI) of animals of both sexes was studied in the testing equipment "Cruciform raised labyrinth". The experimental mechanics of this research part was, as a matter of fact, identical to the one already described for the test "Open field": 30 male Wistar rats $(320-350$ gr., 15.5 - 16 months $)$ and 30 female rats $(270-300$ gr., 15.5 -16 months) with an average level of motion activity and anxiety were selected. The selected animals were divided into 3 groups: "Control" $(n=10)$, "Placebo" $(n=10)$, "Selegiline" ( $\mathrm{n}=10)$ and left under the standard vivarium conditions for a social adaptation. The further operations with the mentioned animal groups were identical to the ones, described for the groups, studied in the "Open field". We should mention that the duration of the animals in the equipment "Cruciform raised labyrinth" was 5 minutes, and before the start of the experiment in the behavioral test, there was also a zero rat. The equipment was wiped with a low-alcohol solution after each animal. AI was calculated by the division of the time indicator of the animals being in the closed arms by the time of animals being in the open arms of the equipment "Cruciform raised labyrinth": TCA/TOA. Therefore, the closer the estimate indicator is to zero, the less the anxiety level of animals is.

All the researches are carried out in the testing complexes "Open field" and "Cruciform raised labyrinth" (Ltd "RPC Open Science"). The experimental video recordings were processed in the software program complex Noldus EthoVision.

The statistical data processing was done in the software program GraphPad 7.0 using Dunn index. The results are presented as a median and $5 / 95 \%$ percentiles.

\section{Results and discussion}

As it was expected, during six-day testing in the "Open field" we observed a slow suppression of animals' motion activity of Wistar rats, which is expressed by the reduction of the passed distance by males by $41 \%(\mathrm{p} \leq 0.01)$ (Fig. $1 \mathrm{~A})$ and the falling of movement speed by $36 \%(\mathrm{p} \leq 0.01)$. The passed distance by female rats was reduced by $46 \%$ $(p \leq 0.05)$ (Fig. 1B), and the movement speed - by $39 \%$ $(p \leq 0.01)$. All the indicators comparisons here and further are presented in relation to the 1 st day.

The analysis of time of two control animal groups in different zones of the "Open field" revealed that despite the sex assignment the time of being in the central zones reduces, and in the wall periphery zone increases, a so called thigmotaxis is observed. For example, the time of being in the centre of the open field reduces by $84 \%$ $\mathrm{p} \leq 0.01)$ for males, and for females - by $81 \%(\mathrm{p} \leq 0.01)$ (Fig. 2).

In Groups "Selegiline" the dynamics of the animals" behavioral activity differed little from the control groups, but a slight (not reaching a significant level) increase of rats' time being in the centre of the "Open field" was observed, as well as dominance of the complete grooming even on the sixth day of testing (Table I). This fact shows a certain improvement of the psycho-emotional background of animals.

In Groups "Control" and "Placebo" of both male and female rats grooming, on the contrary, gains a more evinced interrupted character. This may indicate a growing anxiety of animals. It is necessary to explain that if a definite type of grooming was scarcely distinguished and it was impossible to interpret it, then such behavioral manifestations were not fixed. That is why on some days definite types of grooming got a reference designation "absence", i.e. their duration tended to zero.

It is also necessary to mention that the dynamics of the grooming indicator did not have impressive gender differences; that is why we presented only the table with the data on male rats.

In Groups "Placebo" of both sexes there are no significant differences in the analyzed behavioral indicators from the corresponding dynamics of the control groups' animals. Even at the level of quantitative indicators these dynamics demonstrated a substantial similarity. The mentioned fact points out the absence of any significant influence of additional manipulations, such as intraperitoneal injection of a physiological solution by the syringe for insulin injections, on the rats from these groups.

At the next stage we researched the AI dynamics under daily six-day testing of rats of both sexes on the equipment "Cruciform raised labyrinth". The main working hypothesis was: in case the suppression of the motion activity under daily testing is a consequence of the animals' anxiety level growth, then AI has to increase gradually from the $1^{\text {st }}$ to the $6^{\text {th }}$ day. But the AI dynamics, which was demonstrated by the animals from Groups "Control" and "Placebo" of both sexes, does not allow making an unambiguous conclusion. Thus, the male rats from Group "Control" demonstrated a reliable growth of AI by $23 \%(p \leq 0.05)$ on the $3^{\text {d }}$ day of the experiment and by $27 \%(p \leq 0.05)$ on the $4^{\text {th }}$ day in comparison to the indicator of the $1^{\text {st }}$ day. On the $5^{\text {th }}$ and $6^{\text {th }}$ days intragroup dispersion of the AI indicator was high and did not allow revealing probable differences. Such a high dispersion occurred because these days some of the group representatives spent enough time in the open arms of the cruciform raised labyrinth, others - in the closed arms. And this preference of each animal became pronouncedly asymmetric.

An analogous situation was observed in Group "Placebo" of the male rats with the difference that AI was reliably higher than the values of the $1^{\text {st }}$ day on the $4^{\text {th }}$ and the $6^{\text {th }}$ days (by $24 \%$ and $32 \%$ at $p \leq 0.05$ correspondingly). 

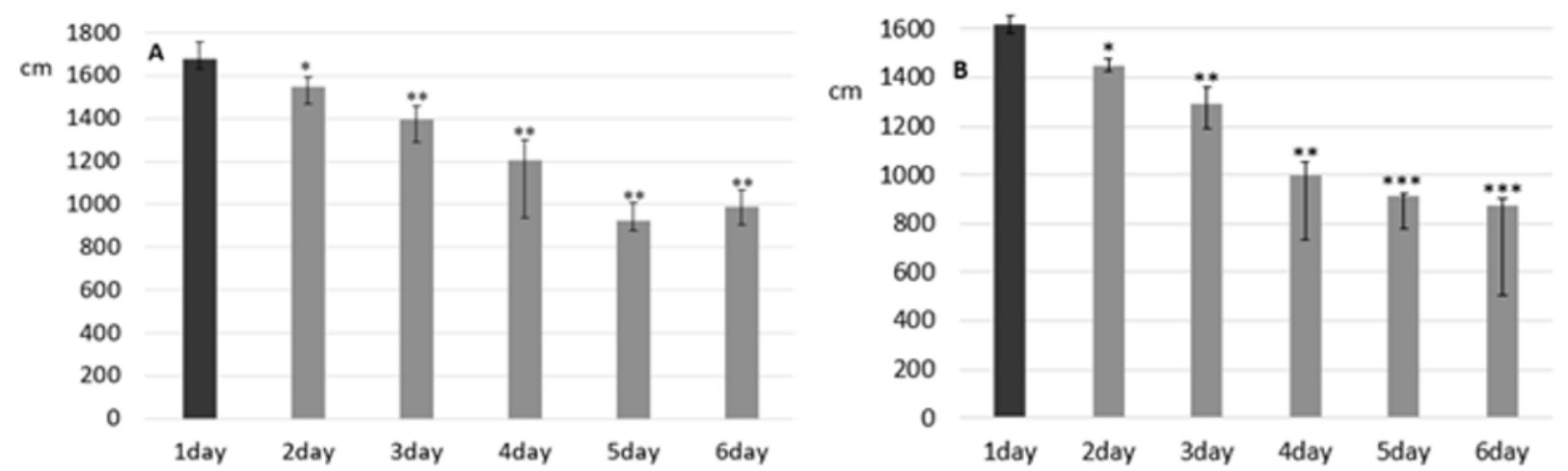

Fig. 1. The change of the passed distance in the "Open field" under daily testing of male rats (A) and female rats (B) in control groups.

Notes: the values of the median and $5 \% / 95 \%$ percentiles are presented, ${ }^{*}$ - the differences from the indicators of the $1^{\text {st }}$ day at $\mathrm{p} \leq 0.05,{ }^{* *}-$ the differences from the indicators of the $1^{\text {st }}$ day at $\mathrm{p} \leq 0.01, * * *$ - the differences from the indicators of the $1^{\text {st }}$ day at $p \leq 0.001$.

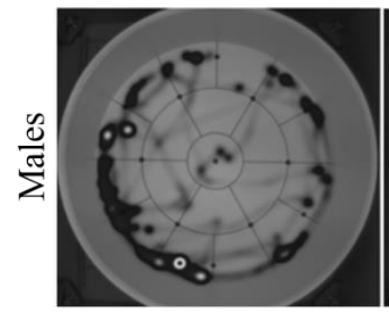

$1^{\text {th }}$ day

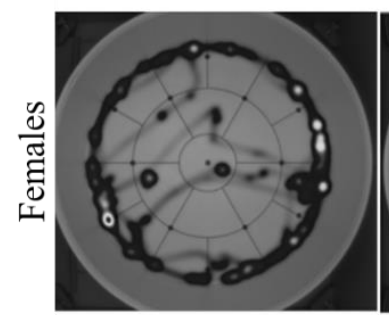

$1^{\text {th }}$ day

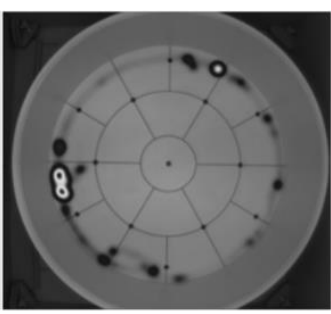

$6^{\text {th }}$ day

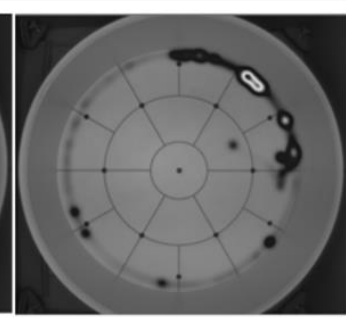

$6^{\text {th }}$ day
Fig. 2. The thermal maps of male rats and female rats movement in the open field in the control groups.

Note: the intensity of colouring and transition to warm colours is in direct proportion to the time of animals being in the field space.

In the group of male rats "Selegiline" AI remained stable enough during the first four days of the research, but by the $5^{\text {th }}$ day of testing the animals of this group started actively jumping off the open arms of the cruciform raised labyrinth down the floor; and this did not allow doing an adequate analysis of the data. The existence of this fact is an extremely important manifestation which indicates a low anxiety level of the animals of this group. The male rats of Group "Selegiline" start demonstrating practically fearlessness of height which is the main limit in the cruciform raised labyrinth and provides the methodological efficiency of this equipment. Therefore, in connection with the described situation, we considered unreasonable to do a comparison between AI dynamics of different groups of male rats.

The second most important meaningful point of the described experimental fact is that the suppression of the motion activity of rats under daily testing in the open field is unlikely to be explained by the growing anxiety of animals.
The behavioral indicators of the female rats in the cruciform raised labyrinth were noticeably more stable in Group "Selegiline" AI was stable enough, and only one case of jumping down the floor was registered on the 5 th day of the research. The AI dynamics of Groups "Control" and "Placebo" was identical: the indictor grew on the $3 \mathrm{~d}$ day and the 6th day of the research; and there were no reliable differences on any of these days.

It is not difficult to foresee that the reliable differences in the AI dynamics of the female rats will be registered on the $5^{\text {th }}$ and $6^{\text {th }}$ days of the research between Group "Selegiline" and Group "Control", including "Placebo". The comparison of AI dynamics between the female rats from Groups "Control" and "Selegeline" is presented in Fig. 3.

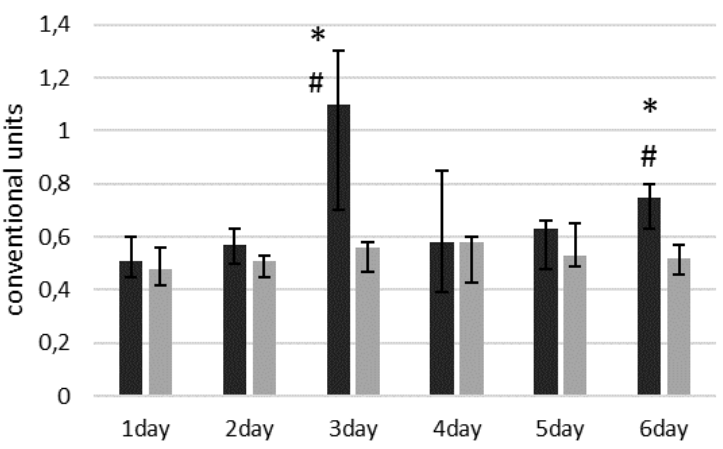

Fig. 3. Comparison of the anxiety index of the female rats from

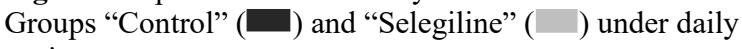
testing.

Notes: \# - the differences between the IA values of Groups "Control" and "Selegiline" at $\mathrm{p} \leq 0.05$; the rest signs are the same as in Fig. 1.

Thus, according to the results of the six-day testing of the female rats there was no obtained unambiguous answer concerning the role of anxiety in the developing suppression of the motion activity of the rats under daily testing. But, as well as for the males, it was shown that the increase of the central dopamine concentration contributes to the AI preservation at a stable level and may cause the suppression of natural fears of animals, for example, fear of height. 
Table 1. Comparison of the average time of male rats' grooming in two groups of "control" and "Selegiline" under 6-day testing in the "open field"

\begin{tabular}{|c|c|c|}
\hline \multicolumn{3}{|c|}{$\begin{array}{l}\text { Interrupted grooming of separate body parts. } \\
\text { The days of testing and an average time of grooming (sec) by Groups are shown: a) Control; b) "Selegiline" and the } \\
\text { significant difference level. }\end{array}$} \\
\hline $1^{\text {st }}$ day & $\begin{array}{l}\text { a) absent } \\
\text { b) absent }\end{array}$ & \\
\hline $2^{\text {nd }}$ day & $\begin{array}{l}\text { a) absent } \\
\text { b) absent }\end{array}$ & \\
\hline $3 \mathrm{~d}$ day & $\begin{array}{l}\text { a) } 18 \pm 1.2 \\
\text { b) absent }\end{array}$ & $(p \leq 0.0001)$ \\
\hline $4^{\text {th }}$ day & $\begin{array}{l}\text { a) } 20 \pm 2.3 \\
\text { b) absent }\end{array}$ & $(p \leq 0.0001)$ \\
\hline $5^{\text {th }}$ day & $\begin{array}{l}\text { a) } 22 \pm 1.8 \\
\text { b) absent }\end{array}$ & $(p \leq 0.0001)$ \\
\hline $6^{\text {th }}$ day & $\begin{array}{l}\text { a) } 23 \pm 1.2 \\
\text { b) absent }\end{array}$ & $(p \leq 0.0001)$ \\
\hline \multicolumn{3}{|c|}{ Incomplete grooming } \\
\hline $1^{\text {st }}$ day & $\begin{array}{l}\text { a) } 24 \pm 1.5 \\
\text { b) } 24 \pm 1.3\end{array}$ & \\
\hline $2^{\text {nd }}$ day & $\begin{array}{l}\text { a) } 25 \pm 2.1 \\
\text { b) } 24 \pm 1.8\end{array}$ & \\
\hline $3^{\mathrm{d}}$ day & $\begin{array}{l}\text { a) } 10 \pm 0.8 \\
\text { b) } 15 \pm 2.6\end{array}$ & $\mathrm{p} \leq 0.01$ \\
\hline $4^{\text {th }}$ day & $\begin{array}{l}\text { a) } 5 \pm 0.4 \\
\text { b) } 10 \pm 1.2\end{array}$ & $\mathrm{p} \leq 0.01$ \\
\hline $5^{\text {th }}$ day & $\begin{array}{l}\text { a) absent } \\
\text { b) absent }\end{array}$ & \\
\hline $6^{\text {th }}$ day & $\begin{array}{l}\text { a) absent } \\
\text { b) absent }\end{array}$ & \\
\hline \multicolumn{3}{|c|}{ Complete grooming } \\
\hline $1^{\text {st }}$ day & $\begin{array}{l}\text { a) absent } \\
\text { b) absent }\end{array}$ & \\
\hline $2^{\text {nd }}$ day & $\begin{array}{l}\text { a) absent } \\
\text { b) } 30 \pm 3.2\end{array}$ & $\mathrm{p} \leq 0.0001$ \\
\hline $3^{\mathrm{d}}$ day & $\begin{array}{l}\text { a) absent } \\
\text { b) } 40 \pm 2.5\end{array}$ & $\mathrm{p} \leq 0.0001$ \\
\hline $4^{\text {th }}$ day & $\begin{array}{l}\text { a) absent } \\
\text { b) } 44 \pm 1.8\end{array}$ & $\mathrm{p} \leq 0.0001$ \\
\hline $5^{\text {th }}$ day & $\begin{array}{l}\text { a) absent } \\
\text { b) } 42 \pm 2.3\end{array}$ & $\mathrm{p} \leq 0.0001$ \\
\hline $6^{\text {th }}$ day & $\begin{array}{l}\text { a) absent } \\
\text { b) } 43 \pm 3.6\end{array}$ & $\mathrm{p} \leq 0.0001$ \\
\hline
\end{tabular}

\section{Conclusion}

Therefore, the increase of the central dopamine concentration under the blockade MAO-B does not counteract the process of the motion activity lowering of the aging Wistar rats of both sexes, which was observed under daily testing, at least, in the concentration, forming after one hour of injecting the Selegiline, the blockader of MAO-B, in the dose of $5 \mathrm{mg} / \mathrm{kg}$. This assists to form a more stable psycho-emotional background and, probably, is able, more or less, to suppress natural (instinctive) fears of animals. According to this research such suppression had gender differences and was more evinced in the male rats.

Besides, it is possible to ascertain that additional influences of low intensity, in our case it is the intraperitoneal injections of the physiological solution by the syringe for insulin injections into the animals from Group "Placebo", do not change the dynamics of the behavioral reactions of aging rats of both sexes in any way.

We are inclined to interpret the results of this research as the argument for the opinion that the disappearance of the cognitive interest, and not the anxiety increase, plays the key role in the suppression of the motion activity under daily testing of animals in the open field. The following facts are in favor of this opinion:

1. AI in Groups "Selegiline" of both sexes remained stable on the background of the motion activity suppression becoming apparent.

2 . The grooming indicators changes of both sexes animals in Groups "Selegiline" can be interpreted in the direction of a comfortable psycho-emotional state, but not vice-versa.

3. The AI dynamics in Groups "Control" and "Placebo" of both sexes did not demonstrate a steady growth day by day, but rather had a wavy character. 


\section{Acknowledgment}

The research is done on the equipment of the Center for Collective Use "Experimental Physiology and Biophysics" of V. I. Vernadsky Crimean Federal University.

\section{References}

1. A. F. Yakimovskii, I.P. Pavlov Journal of Higher Nervous Activity, 61, 212-218 (2011).

2. A. V. Kalueff, Stress, anxiety and behavior. (Kyiv: Enigma, 1998).

3. E. Nowakowska, K. Kus, A. Chodera and J. Rybakowski, J Physiol Pharmacol., 52, 863-873 (2001).
4. D. F. Smith, Psychopharmacology, 50, 81-84 (1976).

5. D. Schulz, F. A. Henn, D. Petri and J. P. Huston, Neuroscience, 329, 83-92 (2016).

6. M. N. Gordon, C. D. Muller, K. A. Sherman, et al., Pharmacol. Biochem. Behav, 63, 501-506 (1999).

7. A. Barbelivien, L. Nyman, A. Haapalinna and J. Sirviö, Basic Clin. Physiol. Pharmacol., 88, 304-312 (2001).

8. S. Amiri, H. Amini-Khoei, A. Mohammadi-Asl et al., Physiology \& behavior, 163, 107-114 (2016).

9. R. Pascual and S. P. Zamora-León, Dev. Neurosci., 29, 261-267 (2006). 